\title{
A case for including sepsis identification in first aid education
}

Jeffrey L. Pellegrino

Over 34 million people globally suffer sepsis, with 6 million adult deaths and 78,000 children/neonates. The burden of those who survive includes missing limbs, organ dysfunction, and cognitive/memory losses. When a person's response to infection becomes dysregulated, organ dysfunction becomes life threatening. Once circulatory and organ failure begins, septic shock, time to definitive care requires a successful flow through the Chain of Survival Behaviors, within an hour.

Survival decreases within the first hour after onset of hypotension. First aid education can raise the level of awareness and skills in early recognition of the signs of infection (pneumonia, urinary tract infection, abdominal distension/diarrhea, meningitis, or cellulitis/wound infection) along with a combination of elevated body temperature $\left(>38.3^{\circ} \mathrm{C}\right)$, increased heart rate $(>90 / \mathrm{min})$, labored/difficulty breathing $(>20 / \mathrm{min})$, or altered mental status. International guidelines need to be developed for age specific signs and symptoms, which need to be communicated to vulnerable populations in meaningful ways.

Implications of educating individuals to recognize sepsis leads to understanding the learner's Emergency Medical Services (EMS) options or how to bring definitive care to the ill person, which will differ in EMS rich and poor communities. Additional education outside of early recognition, like locating appropriate care, will need to be built to enhance the chain of survival behaviors, which will be important to training organizations in various populations.

\section{Conference Engagement}

Through the Chain of Survival Behaviors we challenged all ourselves to look at the science and messaging to two different audiences, communities with developed EMS and those without. Participants focused on prevent and prepare messages in populations without EMS because of the context and having the maximum opportunity to reduce risks and find professional help. These included hygiene, early signs, and plans for bringing help to or for evacuation. In EMS served communities a series of public health messages were conceived along with picture and mnemonic tools for early recognition. Various sub-populations, including children and the elderly were considered during the conversation and across national cultures represented in the room.

\section{References}

Fleischmann-Struzek, C., Goldfarb, D. M., Schlattmann, P., Schlapbach, L. J., Reinhart, K., \& Kissoon, N. (2018). The global burden of paediatric and neonatal sepsis: a systematic review. The Lancet. Respiratory Medicine, 6(3), 223-230. https://doi.org/10.1016/S2213-2600(18)30063-8

Fleischmann, C., Scherag, A., Adhikari, N. K., Hartog, C. S., Tsaganos, T., Schlattmann, P., ... Reinhart, K. (2015). Global burden of sepsis: a systematic review. Critical Care VO - 19, (42). https://doi.org/10.1186/cc14101 
International Federation of Red Cross Red Crescent Societies. (2016). International first aid and resuscitation guidelines 2016. Geneva, Switzerland: International Federation of Red Cross Red Crescent Socieites. Retrieved from http://www.ifrc.org/Global/Publications/Health/First-Aid2016-Guidelines_EN.pdf

Kumar, A., Roberts, D., Wood, K. E., Light, B., Parrillo, J. E., Sharma, S., ... Cheang, M. (2006). Duration of hypotension before initiation of effective antimicrobial therapy is the critical determinant of survival in human septic shock. Critical Care Medicine, 34(6), 1589-1596.

Walter, E. J., Hanna-Jumma, S., Carraretto, M., \& Forni, L. (2016). The pathophysiological basis and consequences of fever. Critical Care, 20, 200. https://doi.org/10.1186/s13054-016-1375-5 